\title{
LA INSTITUCIONALIDAD COMO FACTOR DE INCREMENTO O DETRIMENTO DE LA SALUD
}

Néstor Rodríguez Ardila

\section{RESUMEN:}

Análisis realizado por el Director de la Caja de Compensación familiar Compensar Néstor Rodríguez Ardila texto tomado de su intervención en el pasado Foro de Salud, realizado en Paipa Boyacá en el pasado mes de agosto de 2008, el texto hará parte de un libro de memorias de esta conferencia que el politécnico Grancolombiano, la Corporación Escenarios y el departamento de Planeación Nacional publica periódicamente para socializar estas discusiones académicas a una mayor escala. El texto analiza como las políticas públicas que se conciben con el ánimo de preservar la institucionalidad en Colombia pueden generar detrimento en las entidades prestadoras de servicios de salud, analiza los diferentes incentivos que se plantean en el sistema de salud para los colombianos los beneficios y malestares del mismo.

\section{ABSTRACT:}

Analysis made by the Director of the Family Compensation
Fund Compensar, Néstor Rodríguez Ardila. Text taken from his intervention in the last Health Forum, held in Paipa, Boyacá in August 2008. This text will be part of the proceedings of such conference being published periodically by the Politécnico Grancolombiano, the Scenario Corporation, and the National Planning Department in order to socialize these academic discussions widely. This text analyzes the way public policies, conceived to preserve the institutional environment in Colombia, can generate the detriment in those institutions that provide health services. It also analyzes the different incentives considered in the Colombian health system along with its benefits and problems.

\section{PALABRAS CLAVE:}

Salud, recursos, finanzas, institucionalidad

\section{KEYWORDS:}

Health, resources, finances, institutional environment
Es necesaria una reflexión sobre el tema de la institucionalidad, a partir de la base de aceptar la existencia de una arquitectura interesante y adecuada en el nivel macro sobre lo que es el sistema de salud o la manera como Colombia ha elegido resolver los desafíos del sector. No obstante, esta arquitectura no basta mientras no se supe- ren diversos escollos, entre ellos la ausencia de un diseño conceptual claro sobre la articulación del sistema.

El punto de referencia podría ser el concepto general de institucionalidad en el esquema teórico del premio Nobel de Economía Douglas North. En términos generales, North define como instituciona- 
lidad al conjunto de reglas formales (como leyes y normas) e informales (como códigos de conducta) que estructuran el conjunto de incentivos de un país bajo los cuales las personas modulan su comportamiento. Es decir, las instituciones que incentivan a que los agentes económicos sean productivos, impulsan el crecimiento económico. De manera análoga, las instituciones que castigan o desincentivan a los agentes productivos, generan mala asignación de recursos, pobreza y corrupción.

Según su teoría, lo que hace que los países avancen es la forma como se logra articular en forma positiva el sistema productivo con lo que hace la gente y la forma como ésta se relaciona entre sí, por medio de la institucionalidad. Esta articulación produce una serie de transacciones no solo económicas sino también sociales y culturales que son las que finalmente determinan si un país es capaz o no de acrecentar la riqueza, objetivo final del proceso, o si simplemente mantiene un nivel estático de riqueza, del cual intentan apoderarse por la fuerza los diferentes grupos de interés.

Naturalmente, los diversos tipos de institucionalidad generan distintos incentivos y costos de transacciones que a la postre determinan o influencian la manera como se distribuyan los recursos.

\section{INCENTIVOS PERVERSOS}

En nuestro caso particular se trataría de

\section{RESEÑA DEAUTOR}

NéstorRodríguezArdila(neridriguez@compensar.com). Director de la Caja de Compensación familiar Compensar, es licenciado en filosofía y letras, con un magíster en economía. Lleva 25 años en Compensar. Está comprometido con la filosofía de brindar bienestar no sólo a los afiliados, sino a las poblaciones más vulnerables del país. En la entidad se ha desempeñado como subdirector operativo y, posteriormente, de planeación. analizar si nuestra institucionalidad avanza hacia el objetivo final de incrementar la salud de los colombianos, o si por el contrario, propicia su detrimento.

Mi punto de vista es que hay una arquitectura institucional con la cual mal que bien estamos relativamente de acuerdo, a pesar de algunas diferencias y debates pendientes como los abordados en este foro.

El problema es que a pesar de contar con esa arquitectura macro, no hay una dirección clara, no hay una línea de pensamiento sobre la forma en que esa arquitectura pueda generar la articulación ni los incentivos necesarios para incrementar la salud.

Y como no se cuentan con claridades ni reflexiones a ese nivel, el resultado es que se crean incentivos perversos en la relación de los actores del sistema, que se traducen en tensiones, conflictos, cuellos de botella y deficiencias generales.

Aunque parezca elemental y obvio, la forma como funciona esta arquitectura olvida o soslaya el hecho de que todo el sistema está movido por la gente y por las transacciones y los motivos que la estimulan. Y mientras no se diseñen esquemas de incentivos positivos y articulación armónica entre los actores, no habrá avances ni en el fortalecimiento institucional ni en la generación de riqueza, en este caso, de riqueza de salud para los colombianos.

Obviamente, al persistir este vacío se confirman los diagnósticos presentados en este foro según los cuales, a pesar de contar con una arquitectura general coherente, en la práctica no hay un concepto de sistema, no fluye la información, no hay articulación entre los actores y cada cual trabaja por su lado y por sus propios intereses. 
Aunque el esquema institucional de salud en apariencia está resuelto en Colombia, si se mira con detenimiento ello no es tan claro ni tan cierto. Porque si fuera cierto y si las reglas de juego fueran claras y sostenibles, se tendría como resultado un incremento en la productividad para el sector y un incremento de la salud y no una lucha por apropiarnos de la misma riqueza sin hacerla crecer. Infortunadamente, a mi modo de ver, esto último es lo que está ocurriendo.

\section{EL PAPEL DEL MINISTERIO: RECTOR, NO ACTOR}

En ese sentido, me atrevo a sintetizar las condiciones generales que permitirían corregir esta situación: en primer lugar, se requiere un Ministerio de Salud (hoy Ministerio de la Protección Social) fuerte en el diseño de aspecto como lo conceptual estructural, el sistema y su conjunto, el micro, el sistema de incentivos, el análisis de los costos de transacciones y de la articulación armónica y eficaz entre los diversos actores.

Es importante comprender que el ministerio no es un actor interesado ni debe pretender serlo, sino que precisamente debería ser el diseñador principal, el rector por excelencia del proceso de articulación y funcionamiento del sistema para que el proceso genere el incremento de salud que todos esperamos.

No me atrevería a decir que ello se lograría volviendo al esquema de un ministerio exclusivamente dedicado a la salud, como ocurría antes, y como han propuesto algunos participantes en este foro. Sea esta u otra alternativa, lo que sí es evidente es la necesidad de que exista un ministerio que asuma su rol en propiedad, no solo en lo macro sino también considerando cuáles son los incentivos y los costos de transacciones, entre otros aspectos.

En ese sentido, no se puede perder la esperanza de que la Comisión de Regulación en Salud (CREs) pueda generar cambios que permitan solventar las deficiencias diagnosticadas en el sector. Como se sabe, la Cres, junto con el Ministerio de Protección Social (Mrs) y el Consejo Nacional de Seguridad Social en Salud (CNsss), hace parte de los organismos de dirección, vigilancia y control del Sistema general de seguridad social en salud (Sgsss).

Es importante que se analice la conveniencia de una Cres fuerte, autónoma y capaz de producir una regulación adecuada. Esta debería trabajar de manera estrecha y coordinada con una Superintendencia encargada de vigilancia y calidad, como condición fundamental para regular precisamente la operación que ha sido diseñada.

\section{SISTEMA DE INFORMACIÓN: NADA EN QUINCEAÑOS}

Es imposible aspirar al fortalecimiento de una institucionalidad eficaz si no se cuenta con un sistema de información sólido, confiable y actualizado, tal como se ha denunciado con insistencia en este foro. Coincido con los panelistas que condenan el hecho de no contar aún con este sistema, después de quince años de haber emprendido la tarea. Ese lapso es demasiado tiempo como lo es también demasiado el daño que causa la ausencia de información confiable y actualizada.

En la actualidad se avanza en un proceso de identificación de beneficiarios, de incorporaciones y de enrolamiento que
Aunque el esquema institucional de salud en apariencia está resuelto en Colombia, si se mira con detenimiento ello no es tan claro nitan cierto. 
el ministerio intenta orientar con buena intención, pero hace falta una concertación y una gestión mucho más decidida. Porque finalmente la salud es un tema prioritario del desarrollo nacional y como tal merece celeridad la consolidación de un pilar tan esencial como es la información.

\section{FLUJO DE RECURSOS FINANCIEROS}

Un tema crucial es el flujo de los recursos financieros. Todos los actores del sistema debemos analizar y concertar mecanismos para solucionar este gravísimo cuello de botella que pone en riesgo tanto el funcionamiento vertebral del sistema como la eficacia de los actores individuales $y$, por ende, la salud de los colombianos.
Desde el punto de vista de la institucionalidad, se requieren acuerdos viables y responsables sobre la manera de encarar el problema del flujo financiero ya que este es fundamental para que el sistema fluya $y$ no siga marchando a "trancazos", como ha sido la experiencia de los últimos años.

Finalmente, al cabo de quince años e infortunadamente como fruto de la mala experiencia, nos vamos dando cuenta que todos los actores del sistema somos parte de la misma cadena. Y, por tanto, no tiene sentido seguir "dándonos garrote" entre sí: al final todos vamos a sucumbir si el sistema naufraga o llegaremos a un puerto saludable si trabajamos en equipo. 